\title{
MONITORAMENTO, ESPACIALIZAÇÃO E CARACTERIZAÇÃO DOS MOVIMENTOS DE MASSA NAS ENCOSTAS DA RODOVIA BA 099 (SUBAUMA-IMBASSAÍ)
} \author{
Ailana da Silva Mendes; Carlos César Uchôa de Lima²; Jornis Vilas Boas Santos ${ }^{3}$
}

1. Bolsista PIBIC/CNPq, Graduando em Engenharia Civil, Universidade Estadual de Feira de Santana, e-mail: ailanamendes@hotmail.com

2. Orientador, Departamento de Exatas, Universidade Estadual de Feira de Santana, e-mail: uchoamaster@gmail.com 3. Participante do projeto, Departamento de Tecnologia, Universidade Estadual de Feira de Santana, e-mail: jorn is@hotmail.com

PALAVRAS-CHAVE: Neotectônica; Movimentos de massa; Recuo de encostas.

\section{INTRODUÇÃOO}

No litoral do Nordeste do Brasil, a unidade estratigráfica denominada Formação Barreiras é constituída de sedimentos que datam do Neógeno e afloram ao longo de toda área costeira. A BA-099, também conhecida como Linha Verde, possui em suas margens, várias encostas compostas por sedimentos da Formação Barreiras. A essa formação, vários autores propõem que ela foi marco de eventos do neotectonismo no Brasil, apresentando zonas de fraqueza, o que possibilita a ocorrência de movimentos de massas. Isso requer, portanto, trabalhos de contenção, que evitem obstrução das estradas, principalmente nos períodos chuvosos. Nos últimos anos, vários trabalhos voltados para as causas do recuo de encostas e, consequentemente movimentos de massa nas encostas da BA099, litoral Norte da Bahia, têm sido desenvolvidos (DANTAS ET AL, 2007; DANTAS \& LIMA, 2008; LIMA ET AL 2008; LIMA 2010).

Essas encostas apresentam grande quantidade de estruturas geológicas, principalmente as juntas e secundariamente as falhas e sismitos (COELHO \& LIMA 2006, LIMA ET, AL 2008). A maior frequência das juntas faz com que as mesmas se constituam nas principais zonas de fraqueza, onde ocorrem os movimentos de massa, provocando recuo das encostas e, em muitos casos, obliterando as rodovias. Muitos fatores explicam a ocorrência dos movimentos de massa em encostas, entretanto, os planos de fraqueza oriundos da ação do neotectonismo é um fato relevante a ser considerado.

Este trabalho foi realizado ao longo da linha verde, - BA 099 - no trecho entre as localidades de Subaúma a Imbassaí e teve como objetivo, o levantamento e monitoramento dos deslizamentos de massa que ocorreram naquela região. Esses acontecimentos podem ter ocorrências naturais e constantes, devido à ação de agentes externos que proporcionam a alteração do cenário geológico, mas podem ser provocadas pela modificação da inclinação das encostas, a partir dos taludes de corte nas margens da rodovia. Assim, foi dada continuidade ao estudo das características das encostas e dos movimentos de massa, sejam eles, apenas de ocorrência natural ou que tenham sido gerados pela intervenção humana. Foram levados em consideração os trabalhos realizados desde 2011 e os estudos iniciados em 2015.

\section{MATERIAL E MÉTODOS OU METODOLOGIA (ou equivalente)}

1- Levantamento bibliográfico, que deverá se realizar durante toda a pesquisa;

2- Desenvolvimento de trabalhos de campo com a identificação, caracterização e quantificação dos movimentos de massa;

3- Serão utilizados instrumentos como: bússola geológica de Brunton, o GPS e a câmera fotográfica. 
4- Análise em laboratório, dos dados coletados e dos resultados obtidos em campo, com a utilização de imagens para a espacialização dos movimentos de massa;

5- Comparativo dos dados obtidos no ano de 2012

6- Elaboração de artigos para a divulgação dos resultados em eventos e elaboração dos relatórios parcial e final.

\section{RESULTADOS E/OU DISCUSSÃO (ou Análise e discussão dos resultados)}

Segundo Selby (1990), movimento de massa gravitacional é o movimento de solo ou material rochoso encosta abaixo sob a influência da gravidade, sem a contribuição direta de outros fatores como água ou ar. As ocorrências dos movimentos de massa se devem à susceptibilidade do terreno segundo fatores predisponentes, associados à ação de atributos deflagradores. (Oliveira, Marcelo Tuller), sendo estes: presença de fraturas geológicas, encostas de constituição arenosa, a inclinação do corte do talude e sua altura estimada.

Foram analisadas cinco encostas, nomeadas de "Imba (número da encosta)", levando em consideração as seguintes características: textura dos sedimentos, altura, distância para a rodovia, altitude, presença ou não de crostas ferruginosas e o tipo de movimento de massa presente.

Dos taludes de corte estudados, dois apresentaram registros de movimentos de massa e serão destacados a seguir.

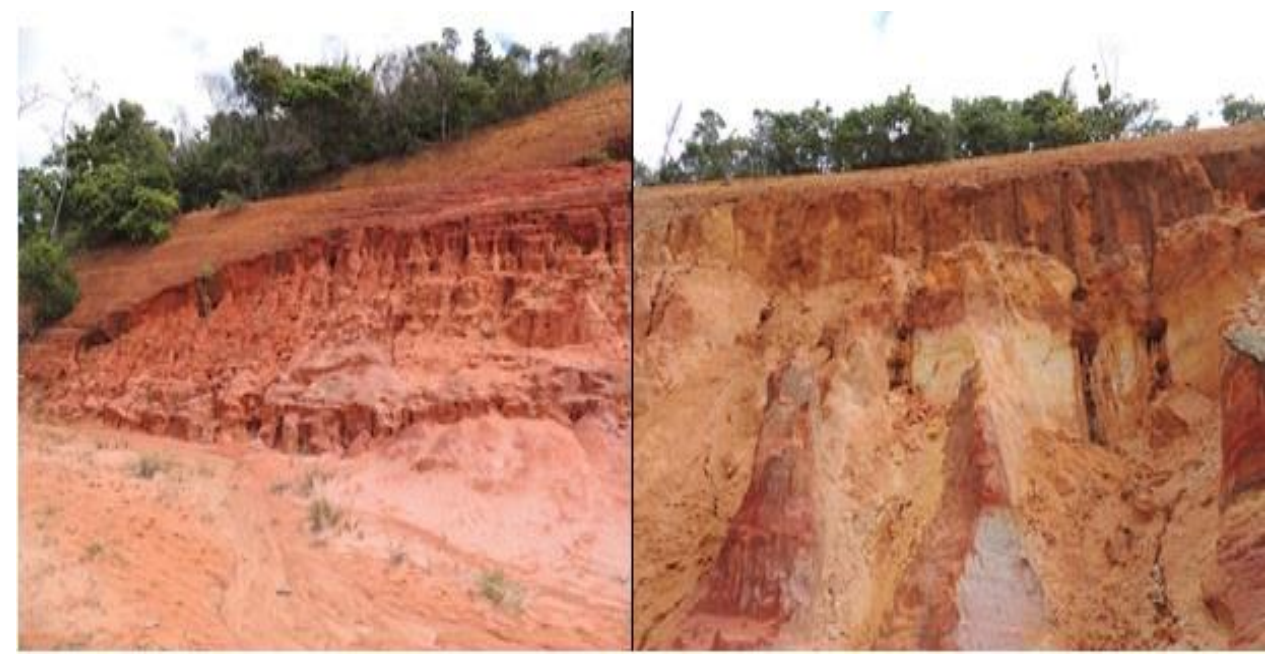

Figura 1- Presença de cunha de ruptura. Fonte: Ailana da S. Mendes, 2017.

O afloramento denominado "Imba 01" possui coordenadas UTM 24L 0256658; 8583106, sendo constituído basicamente por areia fina e pouca argila disposta em algumas camadas e apresenta uma estrutura sedimentar com laminação paralela. Sua altura estimada é 25 metros, sua localização é relativamente afastada da rodovia, e sua altitude, medida da parte superior da berma, é de 43 metros.

$\mathrm{Na}$ encosta estudada, foi possível verificar a presença do movimento translacional (deslizamento de detritos) dispostos em forma de leques na base da encosta, evidenciado pela presença da superfície de fraqueza. Há a presença, em menor quantidade, de queda de blocos e de alguns blocos na iminência de tombar; no entanto, essa análise é mais difícil de ser enfatizada devido ao fato de o material que compõe a encosta ser muito fino e desegregar facilmente. O principal movimento de massa visualizado foi o rotacional, perceptível pela formação de uma cunha de ruputura presente em certos pontos do afloramento, porém, não há um rebaixamento muito alto e o movimento não ocorreu em toda a extensão. 
A vegetação observada acima da encosta, atua como fator importante na preservação do talude pois aumenta a resistência contra a erosão superficial (Fonseca, 1981, Geallatley et al, 1995) pelo desenvolvimento de uma camada protetora, formada pela malha de finas raízes próxima à superfície (Fonseca, 1981; Coppin e Stiles, 1995; Morgan e Rickson, 1995; Sharma, 1996), através do incremento da coesão do sistema solo-raíz e associação das raízes com os caules pode exercer funçaõ de escoras do solo do talude (Gray, 1995)

Há, ainda, a presença de crostas ferruginosas em certos pontos do afloramento, sendo uma característica típica dos taludes dessa região. As crostas ferruginosas agem de modo a consolidar o material por meio do processo de laterização e formação dos hidróxidos de ferro, culminando numa superfície resistente à erosão.

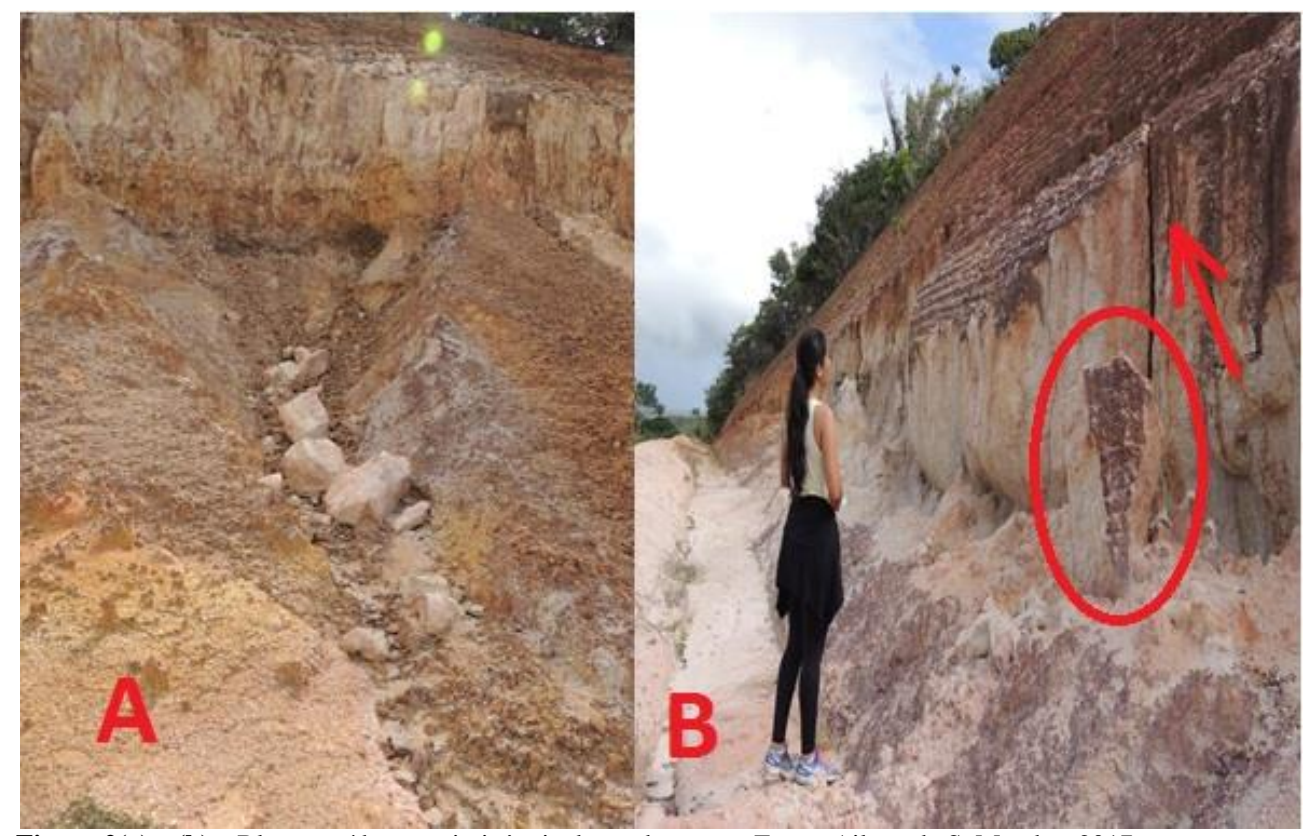

Figura 2(a) e (b) - Blocos caídos e na iminência de tombamento. Fonte: Ailana da S. Mendes, 2017.

A figura 2 refere-se à encosta denominada "Imba 05", cuja coordenadas UTM é 24L 0613786; 8622596, e elevação igual a 51 metros. Sua constituição é dada por areia fina com lâminas de argila, e localiza-se a uma distância relativamente afastada da pista.

Foi observada a presença de queda de blocos, caracterizada na figura 2 (a) por pequenos aglomerados rochosos, dispostos em toda a extensão da encosta. Além disso, a presença das zonas de fraqueza assume um papel preponderante na configuração dessa encosta, como mostrado na figura 2 (b); essas fraturas geológicas facilitam a percolação das águas de infiltração e posterior erosão do talude, assim sendo, a percolação do fluído culmina no surgimento de blocos que estão sujeitos a tombamento.

O afloramento é caracterizado pela verticalização dos paredões que se dá a partir da percolação da água da chuva nas fraturas geológicas. A água, como agente ativo, atua no processo de erosão através do efeito de infiltração e de escoamento. No caso estudado, as águas irão infiltrar mais comumente, nas fraturas, dando lugar a movimentos de remoção de materiais quando a umidade excessiva provoca a perda de coesão do solo, excedendo os limites de plasticidade ou de liquidez (Gomes, F. S., 2001). No caso das águas de escoamento, elas veiculam pela superfície do terreno, em enxurradas de forma difusa, laminar ou concentrada, provocando a formação de ravinas, que podem evoluir para voçorocas. (Mendes, 2016) 


\section{CONSIDERAÇÕES FINAIS (ou Conclusão)}

Os estudos realizados ao longo da BA 099 revelaram que alguns fatores podem facilitar a ocorrência dos movimentos de massa, destacando-se: (a) presença de fraturas geológicas, (b) encostas de constituição arenosa, (c) a inclinação do corte do talude. De outro modo, alguns outros parâmetros, podem contribuir para a manutenção da encosta, tais como: (a) a cobertura vegetal, (b) a presença de crostas férricas, e (c) encostas de constituição argilosa. Todos esses fatores condicionantes foram observados nos diferentes afloramentos visitados.

Foram observados diferentes tipos de movimentos de massa na região, tais quais: queda de blocos, tombamento, escorregamento rotacional e escorregamento translacional. Estes eventos não apresentam grande risco à BA 099, já que, a distância das encostas estudadas para as rodovias é relativamente alta e os movimentos de massa, não tem dispersado grandes quantidades de solo e sedimentos.

\section{REFERÊNCIAS}

AHRENDT, A. Movimentos de Massa Gravitacionais - proposta de um sistema de previsão: aplicação na área urbana de Campos do Jordão - SP. Tese (Doutorado) Escola de Engenharia de São Carlos, Universidade de São Paulo. São Carlos, 2005.

GOMES, F.S. Estudo da Erodibilidade e Parâmetros Geotécnicos de um Solo em Processo Erosivo. Dissertação (Mestrado). Universidade Federal de Pernambuco Centro de Tecnologia e Geociências. Mestrado em Engenharia Civil, 2001.

GUIDICINI, G. \& Nieble, C. M. Estabilidade de Taludes Naturais e de Escavação. $2^{\text {a }}$ edição, S. Paulo, SP, 1993.

DANTAS, J.J.R., LIMA, C.C.U., COELHO M.G.A., Avaliação Tectônica Preliminar do Grupo Barreiras no Extremo Norte do Litoral da Bahia, Brasil. In XI Congresso da ABEQUA, Belém, 2007.

DANTAS, J.J.R \& C.C.U. LIMA. As Juntas Tectônicas e a Evolução das Encostas no Extremo Norte do Litoral da Bahia, Brasil. In SINAGEO VI, Belo Horizonte, 2008.

LIMA, C.C.U.; DANTAS, J.J.R.;COELHO,M.G.A. Fragilidades tectônicas nas encostas das rodovias litorâneas de Sergipe e Extremo Norte da Bahia. Universidade Estadual de Feira de Santana, UEFS - Feira de Santana, 2008.

COELHO, M.G.A. \& LIMA, C.C.U. Análise tectônica preliminar do Grupo Barreiras no litoral norte do Estado de Sergipe. In: Simpósio Nacional de Geomorfologia, 6, Goiânia 7p. 2006.

OLIVEIRA, T. Marcelo. Estudo de movimentos de massa gravitacionais no município de. Belo Horizonte, MG. 2009.

LEMES, M.R.T. Revisão dos efeitos da vegetação em talude. Porto Alegre, 2001.

MENDES, A.S. Monitoramento, especialização e caracterização dos movimentos de massa nas encostas da rodovia BA 099 (Conde-Subaúma), Feira de Santana, Bahia, 2016. 